\title{
BIOFILTRATION COMBINED WITH NON-THERMAL PLASMA FOR AIR POLLUTION CONTROL: A PRELIMINARY INVESTIGATION
}

\author{
M. SCHIAVON ${ }^{1}$, M. SCHIORLIN ${ }^{2}$, V. TORRETTA ${ }^{3}$, M. RAGAZZI ${ }^{1}$ \& E.C. RADA ${ }^{1}$ \\ ${ }^{1}$ Department of Civil, Environmental and Mechanical Engineering, University of Trento, Italy. \\ ${ }^{2}$ Leibniz Institute for Plasma Science and Technology (INP Greifswald), Germany. \\ ${ }^{3}$ Department of Biotechnologies and Life Sciences, University of Insubria, Italy.
}

\begin{abstract}
Biological technologies have been often employed to remove volatile organic compounds (VOCs) at low concentrations from air streams. However, biodegradation is very sensitive to variations of inlet concentrations and flow rate that usually occurs in real industrial processes; furthermore, an acclimation period is required by microorganisms to adapt to new conditions of flow rate and concentration. A possible solution to overcome these issues is represented by a pre-treatment with non-thermal plasma (NTP). The synergy between an NTP reactor and a biofilter in removing a mixture of VOCs from air is the object of this paper. A mixture of five VOCs (benzene, ethylbenzene, $p$-xylene, $n$-heptane and toluene) and humid air was chosen to represent the gaseous effluent stripped from an industrial wastewater treatment plant. A sudden increase in the VOC concentrations was intentionally induced to understand if NTP can manage peaks of the inlet concentration of pollutants and help the biodegradation carried out in the biofilter. NTP revealed to be capable of both pre-treating concentrations peaks and converting the initial VOCs in more soluble compounds; in conclusion, NTP is able to help biodegradation, allows controlling unsteady conditions and prevents stress to bacteria.

Keywords: air pollution control, biofilter, catalysis, industrial wastewater, volatile organic compounds.
\end{abstract}

\section{INTRODUCTION}

Volatile organic compounds (VOCs) are organic chemicals characterized by low boiling point and, consequently, high vapour pressure. Different authors and organizations have proposed different definitions of VOCs, based on different reference boiling points or vapour pressures at a specific temperature: for instance, according to Art [1], a VOC is a hydrocarbon whose boiling point is $<100^{\circ} \mathrm{C}$; the Directive $1999 / 13 / \mathrm{EC}$ of the European Community defines a VOC as an organic compound having a vapour pressure $>0.01 \mathrm{kPa}$ at $20^{\circ} \mathrm{C} \mathrm{[2]}$; according to the Directive 2004/42/EC, a VOC is an organic compound having a boiling point $\leq 250^{\circ} \mathrm{C}$ at a standard pressure of $101.3 \mathrm{kPa}$ [3].

In addition to nuisance due to their odour impact, exposure to VOCs by inhalation may cause severe health effects on humans, depending on the type of exposure (short- or longterm) and on the nature of VOCs (carcinogenic or non- carcinogenic).

The local air quality depends on several factors: local climate (e.g. wind intensity and prevailing directions, atmospheric stability, rainfall, temperature), characteristics of the emission sources (e.g. outgoing mass flow of pollutants, outgoing velocity of the flow, release height) and composition of the exhaust gases (e.g. relative amount of carcinogens). Besides wellknown stationary processes emitting VOCs, such as solvent production manufactures, 
pharmaceutical industry, oil refineries, gas and energy production plants, there are a lot of activities that release high flows of VOCs at lower concentrations: food processing, composting and other mechanical-biological treatments of solid waste, printing industry, paper mills, industrial wastewater treatments [4-7].

Adsorption and incineration, usually adopted to treat VOCs at high concentrations, are not economically and technically convenient when the aim is to remove VOCs from lowly concentrated streams [8]. In these cases, classic alternatives are represented by absorption and biofiltration. However, water absorption is inefficient when dealing with poorly soluble VOCs; on the other hand, chemical absorption implies the use of chemicals, with consequent higher costs. VOC-contaminated streams at relatively low concentrations can be more easily treated by biological technologies, such as biofilters and biotrickling filters [9]. Nevertheless, biological technologies are very sensitive to fluctuations of the inlet mass loading rate [10], which depends on the air flow rate and on the pollutant concentrations in the waste gas to be treated; furthermore, the microorganisms responsible for biodegradation need enough time to acclimatize to new conditions [11]; in addition, the efficiency of biodegradation is lower in the presence of compounds that are characterized by low solubility in water [7]. As a results, biological methods may become inefficient under unsteady conditions and when dealing with poorly soluble compounds.

To overcome these issues, the VOC-contaminated air flow could be pre-treated by the use of non-thermal plasma (NTP). Plasma is defined by Fridman [12] as 'an ionized gas, a distinct fourth state of matter', in which positive and negative charges of ions and electrons are balanced. The generation of plasma is achieved through application of an electric field to a gas. Two main groups of plasmas can be identified: thermal plasmas (TPs) and NTPs. In TPs, the energy provided to the electric field accumulates in the electrons and then, through Joule heating, is transferred to ions and molecules [12]. On the contrary, in NTPs, time and energy are not sufficient to equilibrate the temperature between ions and electrons through collisions [12]; the energy provided to the system is then almost entirely received by electrons only, whose temperature increases (up to $10^{5} \mathrm{~K}$ ) with respect to ions and molecules [13], while the average plasma temperature is relatively low and slightly higher than the temperature of the incoming gas. High-energy electrons promote molecular dissociation and formation of highly reactive species, depending on the composition of the gas: for instance, in presence of oxygen $\left(\mathrm{O}_{2}\right)$, water and hydrocarbons, ozone $\left(\mathrm{O}_{3}\right)$, hydroxyl radicals and organic peroxide radicals can be respectively formed. The latter can also react with other molecules in the gas, degrading the compounds initially present in the mixture.

NTPs have gained increasing consideration during the last decades because of the opportunities they offer in different fields of application (material engineering, medicine, methane and hydrogen reforming, decontamination and pollution degradation). Due to the complexity of plasma chemistry, most of the studies on NTPs for VOC removal focused on mixtures of air and only one VOC, with the attempt to understand the decomposition mechanisms and the by-products formed [11-16]. Applications of NTPs to assist biofiltration are still inadequate to document the effects of a pre-treatment of a VOC-contaminated air flow.

This paper represents an attempt to provide indications on the feasibility of coupling NTP with a laboratory-scale biofilter and on the results obtainable regarding the removal of a mixture of air and five VOCs, chosen as typical components of real effluents from industrial wastewater processing. In addition to the results obtained, critical operative aspects involving the use of catalysts as a polishing step after NTP are described and discussed in this paper. 


\section{MATERIALS AND METHODS}

A scheme of the experimental and analytical setups is reported in Fig. 1.

\subsection{Experimental setup}

The experimental setup consists in an NTP reactor, a laboratory-scale biofilter and five bubblers, each containing one of the following five VOCs: benzene, ethylbenzene, $p$-xylene, $n$-heptane and toluene. The five bubblers are fed with nitrogen $\left(\mathrm{N}_{2}\right)$ and the $\mathrm{N}_{2}$ flow rates passing through each bubbler were adjusted with dedicated mass flow controllers to assure the desired concentrations of each VOC in the total air flow used in this study, which was set at $0.15 \mathrm{Nm}^{3} \mathrm{~h}^{-1}$. The air flow consists in compressed air blown from outside the laboratory building. The air flow is split into two lines: one passing through an additional bubbler containing distilled water and one that mixes up with the $\mathrm{N}_{2}$ flows enriched with VOCs. These two air flow rates were adjusted with two mass flow controllers in order to keep the relative humidity $(R H)$ of the total flow rate at about 50\%. $R H$ and the temperature $(T)$ of the total flow were daily checked with a digital thermo-hygrometer.

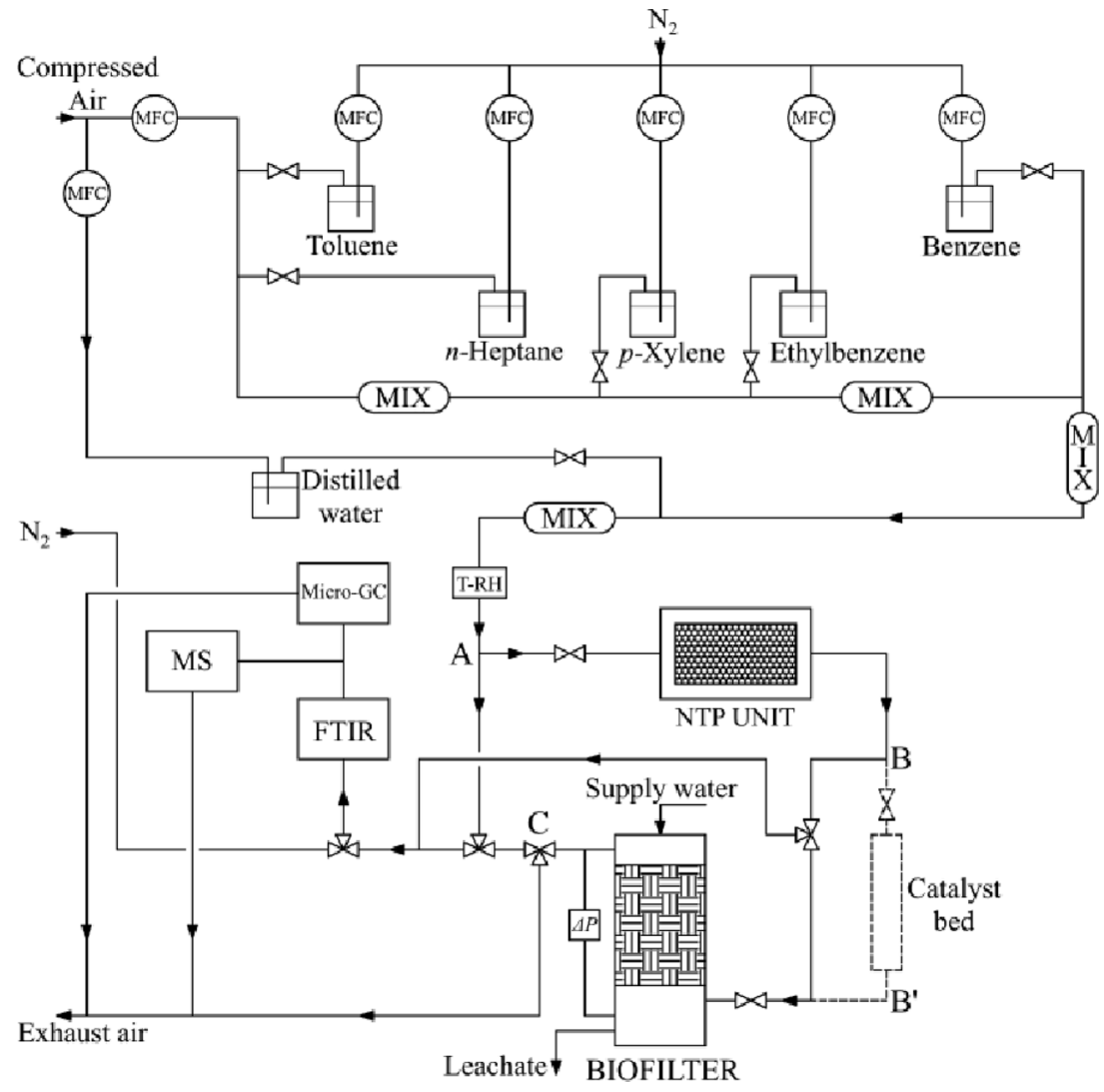

Figure 1: Scheme of the experimental and analytical setups (MFC: mass flow controller; T-RH: thermohygrometer; MIX: mixing chamber). 
After being mixed in appropriate mixing chambers, the $\mathrm{N}_{2}$ flows are mixed with compress air and, finally, with the humid air passed by the bubbler containing distilled water. The total flow was sent directly to the biofilter during the startup phase, i.e. the acclimation period of microorganisms to the VOC mixture. Once the startup phase had been completed, the flow was firstly made passing by the NTP unit for the procedure of the tests.

The NTP unit has a total volume of $0.25 \mathrm{~L}$. Plasma is generated between a layer of dielectric material and the electrodes. The high-voltage electrode is connected to a high-voltage transformer, connected in cascade to an amplifier and a wave form generator.

The biofilter is a PVC cylinder with diameter of $8 \mathrm{~cm}$ and total height of $80 \mathrm{~cm}$. The biofilter was filled with peat till a height of $50 \mathrm{~cm}$. The corresponding empty bed residence time is about $96 \mathrm{~s}$. The filling material was enriched with a lyophilized bacterial inoculum provided by Air Clean Srl (Italy). The biofilter is equipped with a grid supporting the filling material, a connector for the inlet flow placed below the grid, a tap to flush possible excess water collected at the bottom of the biofilter, a connector for the outlet flow located at the top of the biofilter and a connector for the periodical irrigation of the filling material. The pressure drop $(\Delta P)$ between inlet (at the bottom) and outlet (at the top) of the biofilter was monitored with two manometers. The flow exiting the biofilter is sent to an aspiration system. The filling material was irrigated with $25 \mathrm{~mL} \cdot \mathrm{d}^{-1}$ of water.

To prevent possible damages to the microorganisms caused by $\mathrm{O}_{3}$ production in the NTP unit, a catalyst bed made of Carulite ${ }^{\circledR}$ in form of pellets was initially inserted between the NTP unit and the biofilter (Fig. 2).

Catalysts have been often adopted in combination with NTP reactors for pollutant degradation, due to their capability of reducing $\mathrm{O}_{3}$ and of achieving the same removal performance with lower energy consumption.

\subsection{Analytical setup}

A Fourier Transform Infrared (FTIR) spectroscope was used to monitor the concentrations of $\mathrm{O}_{3}$, carbon dioxide $\left(\mathrm{CO}_{2}\right)$ and carbon monoxide $(\mathrm{CO}) . \mathrm{O}_{3}$ and $\mathrm{CO}$ are typical by-products of the application of NTP to $\mathrm{O}_{2}$-containing streams. $\mathrm{CO}_{2}$ is the product of final oxidation by NTP and the product of biodegradation. A mass spectrometer (MS) was used to identify the secondary by-products of VOC degradation by NTP. Finally, a Micro-gaschromatograph (Micro-GC) was used to quantify the five VOCs. Three sampling points were created to sample the flow upstream of the NTP unit (A), upstream of the biofilter (B) and downstream of it (C); an additional sampling point (B') was initially created to sample the flow between the NTP unit and the catalyst bed (Fig. 1).

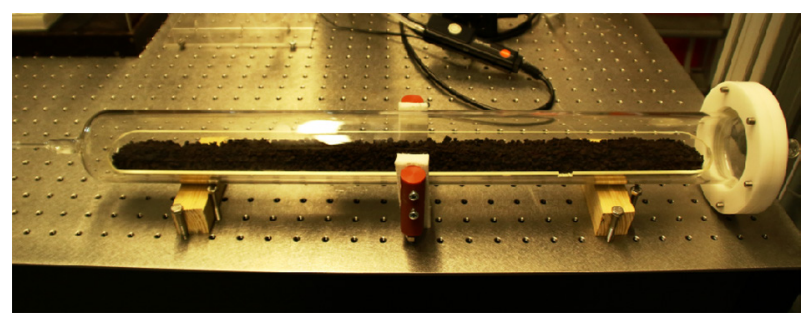

Figure 2: Detail of the catalyst bed. 
The $\mathrm{pH}$ of the filling material was monitored before and after the tests with NTP by means of Litmus stripes.

\subsection{Test procedure}

The startup phase of the biofilter lasted about one month and finished when constant removal efficiencies (REs) were obtained for the five VOCs in the mixture entering the biofilter at the following reference concentrations: benzene: $107 \mathrm{mg} \cdot \mathrm{m}^{-3}$; ethylbenzene: $195 \mathrm{mg} \cdot \mathrm{m}^{-3}$; p-xylene: $255 \mathrm{mg} \cdot \mathrm{m}^{-3}$; $n$-heptane: $190 \mathrm{mg} \cdot \mathrm{m}^{-3}$; toluene: $344 \mathrm{mg} \cdot \mathrm{m}^{-3}$; total VOC concentration: $1,091 \mathrm{mg} \cdot \mathrm{m}^{-3}$.

During the startup phase, the catalyst bed was separately tested in terms of $\mathrm{O}_{3}$ removal, by using an ozonizer as a source of $\mathrm{O}_{3}$ and by measuring the $\mathrm{O}_{3}$ concentration at the FTIR. The catalyst bed showed a $90 \% \mathrm{RE}$ of $\mathrm{O}_{3}$ at the maximal concentration that could be generated by the ozonizer $\left(1,500 \mathrm{mg} \cdot \mathrm{m}^{-3}\right)$.

Before starting the tests involving the application of NTP, the catalyst bed was inserted into the system downstream of the NTP unit. It was decided to perform some tests with the FTIR and with the Micro-GC on the VOC concentrations upstream and downstream of the catalyst bed, in order to understand if the catalyst bed was capable of adsorbing the VOCs contained in the flow. Since the catalyst bed showed a RE of about $70 \%$ on VOCs, it was decided to increase the inlet VOC concentration, to monitor it both in B' and B, and to adjust it to keep the VOC concentrations upstream of the biofilter as close as possible to the reference concentrations, in order to preserve microorganisms from shock. Once the catalyst bed had reached saturation, the inlet VOC concentrations were gradually decreased to the reference values.

Subsequently, a test was performed to investigate how NTP can manage peaks of VOC concentrations and prevent stress to the microorganisms of the biofilter: the VOC concentrations upstream of the NTP unit (A) were increased to $154 \mathrm{mg} \cdot \mathrm{m}^{-3}$ of benzene, $274 \mathrm{mg} \cdot \mathrm{m}^{-3}$ of ethylbenzene, $376 \mathrm{mg} \cdot \mathrm{m}^{-3}$ of $p$-xylene, $266 \mathrm{mg} \cdot \mathrm{m}^{-3}$ of $n$-heptane and $482 \mathrm{mg} \cdot \mathrm{m}^{-3}$ of toluene (total VOC concentration: $1,552 \mathrm{mg} \cdot \mathrm{m}^{-3}$ ); plasma was enlightened and the discharge power was stepwise increased until the total VOC concentration at the inlet of the biofilter got back approximately to the original total VOC concentration.

\subsection{Performance indicators}

To assess the performance of the biofilter, the primary indicator is RE, defined as:

$$
R E(\%)=\frac{C_{\text {in }}-C_{\text {out }}}{C_{\text {in }}}
$$

where $C_{\text {out }}$ is the outlet concentration. The concept of RE is also useful to evaluate the removal performance of an NTP treatment. Another good indicator providing information on the energy consumption of NTP to remove a pollutant is the energy yield (EY), defined as follows:

$$
E Y\left(g \cdot k W h^{-1}\right)=\frac{C_{i n} \cdot R E \cdot M \cdot 3.6}{S E D \cdot V_{m}}
$$

where $M$ is the molar mass of the compound $\left(\mathrm{g} \cdot \mathrm{mol}^{-1}\right)$, SED is the specific energy density, i.e. the power provided to the discharge normalized to $Q, V_{m}$ is the molar volume (which is $24.04 \mathrm{~L} \cdot \mathrm{mol}^{-1}$ at standard conditions) and $C_{i n}$ is expressed as ppm. 


\section{RESULTS AND DISCUSSION}

\subsection{Test of the catalyst bed}

During the test with the inclusion of the catalyst bed, thanks to the sampling points B and B', a desorbing effect of the catalyst was observed, especially when increasing the energy provided to the NTP unit: indeed, since NTP partially converts VOCs to $\mathrm{CO}$ and $\mathrm{CO}_{2}$, the VOC concentration of the flow entering the catalyst decreases when increasing the energy provided to the discharge and the VOCs adsorbed onto the catalysts are released. However, the maximal $\mathrm{O}_{3}$ concentration measured upstream of the catalyst bed (B') was $<580 \mathrm{mg} \cdot \mathrm{m}^{-3}$, which was found as an $\mathrm{O}_{3}$ concentration tolerable by microorganisms [17]. Thus, it was decided to by-pass the catalyst bed and to send the flow directly from the NTP unit to the biofilter.

\subsection{Tests without catalyst bed}

The procedure described in Section 2.3 was repeated with the exclusion of the catalyst bed. The NTP unit was then activated and the SED provided to the NTP unit was varied between $46 \mathrm{~J} \cdot \mathrm{L}^{-1}$ and $128 \mathrm{~J} \cdot \mathrm{L}^{-1}$. The increase in the SED results in a decrease in the VOC concentrations after the NTP treatment (Fig. 3), due to the degradation of VOCs carried out by NTP. At $128 \mathrm{~J} \cdot \mathrm{L}^{-1}$, the total VOC concentration upstream of the biofilter got back to the reference value, i.e. to the initial total VOC concentration.

Some by-products of partial conversion of the initial VOCs were observed downstream of the NTP unit (B), especially styrene, acetophenone, and benzaldehyde. Their solubility in water is higher with respect to the initial compounds. Interestingly, the degradation carried out by NTP can then facilitate biodegradation. NTP demonstrated to be able to reduce the carcinogenic potential of the VOC mixture, since benzene (demonstrated carcinogen) and ethylbenzene (possible carcinogen) were partially converted to traces of styrene (possible carcinogen) and to non-carcinogenic by-products [18]. $\mathrm{CO}$ and $\mathrm{CO}_{2}$ concentrations downstream of the NTP unit (B) varied in the ranges $43-264 \mathrm{mg} \cdot \mathrm{m}^{-3}$ and $900-1,509 \mathrm{mg} \cdot \mathrm{m}^{-3}$, respectively, after increasing the SED from $46 \mathrm{~J} \cdot \mathrm{L}^{-1}$ to $128 \mathrm{~J} \cdot \mathrm{L}^{-1}$.

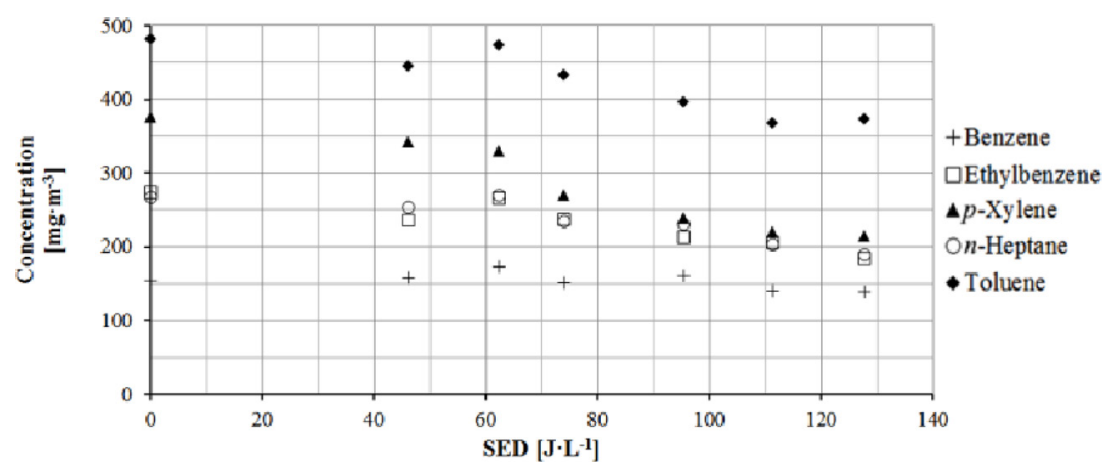

Figure 3: VOC concentrations measured upstream of the biofilter with respect to the SED applied, after increasing the initial concentrations and activating the NTP reactor. 


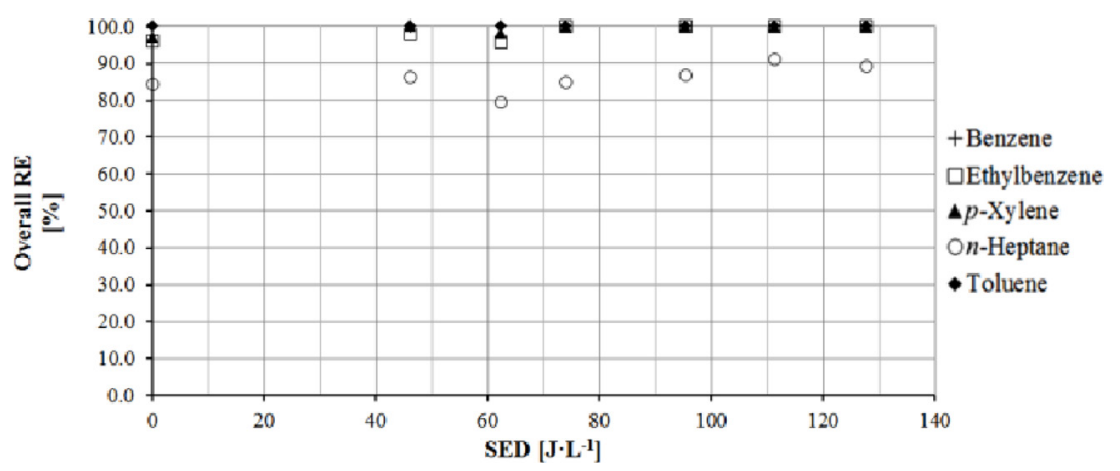

Figure 4: Overall REs of the reference VOCs measured downstream of the biofilter as a function of the SED, after increasing the initial concentrations and activating the NTP reactor.

During the whole experimental activity, whose total duration exceeded 40 days, $\Delta P$ remained below $40 \mathrm{mmH}_{2} \mathrm{O}$ and the $\mathrm{pH}$ did not vary, remaining stable at 7 , thanks to the durability and the buffering properties of the filling material.

Figure 4 presents the global REs related to the combination of NTP with the biofilter with respect to the SED. All VOCs, except for $n$-heptane presented maximal REs $>99 \%$ even at medium SED (74 J.L $\mathrm{L}^{-1}$ ). The RE of $n$-heptane did not exceed $91 \%$; however, this value is higher than the RE obtained with the biofilter alone, at the end of the startup phase, which was $87 \%$.

The maximal EY for benzene, ethylbenzene, $p$-xylene, $n$-heptane and toluene resulted as equal to $0.4,3.1,5.2,2.1$ and $3.7 \mathrm{~g} \cdot \mathrm{kWh}^{-1}$, respectively. Thus, benzene degradation requires more energy compared to the other VOCs.

\section{CONCLUSIONS}

The application of an NTP to a VOC-contaminated stream works in favour of the biodegradation carried out by a biofilter.

In spite of an increase in the initial VOC concentrations, intentionally induced to simulate peaks of pollutant load, the VOC removal carried out by the NTP reactor kept the VOC concentrations at the inlet of the biofilter substantially equal to the original concentrations. This way, the biofilter could operate properly without any stress to microorganisms. In addition, some by-products were formed during the NTP treatment and these were more polar than the original VOCs. Since the low solubility of a compound in water negatively affects the biodegradation by microorganisms, NTP showed encouraging results as an option to help biodegradation in biofilters. The use of catalysts to decrease the energy consumption and/or to reduce $\mathrm{O}_{3}$ should be regarded with caution due to possible desorbing effects, especially when coupling NTP with biofiltration, which is very sensitive to LR perturbations. The next step of this research includes a broader understanding of this synergy: this target could be achieved through inducing higher peaks of concentrations and adjusting the operational parameters of a NTP reactor to preserve the correct operation of a biofilter.

\section{ACKNOWLEDGEMENTS}

This work was supported by the University of Trento (University Research Project P.STR.14 PLAS) and by the European Union Seventh Framework Programme (FP7/2007-2013) under 
grant agreement $\mathrm{n}^{\circ} 312616$. The authors wish to thank Mr. Paolo Caruson, Air Clean Srl and Mr. Wolfgang Reich for the technical and material support to this research.

\section{REFERENCES}

[1] Art, H.W., A Dictionary of Ecology and Environmental Science, Henry Holt and Company: New York, 1993.

[2] European Community, Council Directive 1999/13/EC of 11 March 1999 on the limitation of emissions of volatile organic compounds due to the use of organic solvents in certain activities and installations. Official Journal of the European Communities L, 85, pp. 1-22, 1999.

[3] European Union, Directive 2004/42/EC of the European Parliament and of the Council of 21 April 2004 on the limitation of emissions of volatile organic compounds due to the use of organic solvents in certain paints and varnishes and vehicle refinishing products. Official Journal of the European Union L, 143, pp. 87-96, 2004.

[4] Preis, S., Klauson, D. \& Gregor, A., Potential of electric discharge plasma methods in abatement of volatile organic compounds originating from the food industry. Journal of Environmental Management, 114, pp. 125-138, 2013.

http://dx.doi.org/10.1016/j.jenvman.2012.10.042

[5] Dorado, A.D., Husni, S., Pascual, G., Puigdellivol, C. \& Gabriel, D., Inventory and treatment of compost maturation emissions in a municipal solid waste treatment facility. Waste Management, 34, pp. 344-351, 2014.

http://dx.doi.org/10.1016/j.wasman.2013.10.044

[6] Xie, B., Liang, S.B., Tang, Y., Mi, W.X. \& Xu, Y., Petrochemical wastewater odor treatment by biofiltration. Bioresource Technology, 100(7), pp. 2204-2209, 2009. http://dx.doi.org/10.1016/j.biortech.2008.10.035

[7] Schiavon, M., Scapinello, M., Tosi, P., Ragazzi, M., Torretta, V. \& Rada, E.C., Potential of non-thermal plasmas for helping the biodegradation of volatile organic compounds (VOCs) released by waste management plants. Journal of Cleaner Production, 104, pp. 211-219, 2015.

http://dx.doi.org/10.1016/j.jclepro.2015.05.034

[8] Copelli, S., Torretta, V., Raboni, M., Viotti, P., Luciano, A., Mancini, G. \& Nano, G., Improving biotreatment efficiency of hot waste air streams: experimental upgrade of a full plant. Chemical Engineering Transactions, 30, pp. 49-54, 2012.

[9] Hunter, P. \& Oyama, S.T., Control of Volatile Organic Emissions: Conventional and Emerging Technologies, John Wiley \& Sons: New York, 2000.

[10] Torretta, V., Raboni, M., Copelli, S. \& Caruson, P., Application of multi-stage biofilter pilot plants to remove odor and VOCs from industrial activities air emissions. WIT Transactions on Ecology and the Environment, 176, pp. 225-233, 2013. http://dx.doi.org/10.2495/esus130191

[11] Ragazzi, M., Tosi, P., Rada, E.C., Torretta, V. \& Schiavon, M., Effluents from MBT plants: Plasma techniques for the treatment of VOCs. Waste Management, 34(11), pp. 2400-2406, 2014. http://dx.doi.org/10.1016/j.wasman.2014.07.026

[12] Fridman, A., Plasma Chemistry, Cambridge University Press: Cambridge, 2008. http://dx.doi.org/10.1017/CBO9780511546075

[13] Kim, H.-H., Nonthermal plasma processing for air-pollution control: a historical review, current issues, and future prospects. Plasma Processes and Polymers, 1, pp. 91-110, 2004. http://dx.doi.org/10.1002/ppap.200400028 
[14] Ye, Z., Zhang, Y., Li, P., Yang, L., Zhang, R. \& Hou, H., Feasibility of destruction of gaseous benzene with dielectric barrier discharge. Journal of Hazardous Materials, 156, pp. 356-364, 2008.

http://dx.doi.org/10.1016/j.jhazmat.2007.12.048

[15] Schiorlin, M., Marotta, E., Rea, M. \& Paradisi, C., Comparison of toluene removal in air at atmospheric conditions by different corona discharges. Environmental Science \& Technology, 43(24), pp. 9386-9392, 2009. http://dx.doi.org/10.1021/es9021816

[16] Schmidt, M., Schiorlin, M. \& Brandenburg, R., Studies on the electrical behaviour and removal of toluene with a dielectric barrier discharge. Open Chemistry, 13(1), pp. 477 483, 2015.

[17] Wang, Z., Xiu, G., Qiao, T., Zhao, K. \& Zhang, D., Coupling ozone and hollow fibers membrane bioreactor for enhanced treatment of gaseous xylene mixture. Bioresource Technology, 130, pp. 52-58, 2013. http://dx.doi.org/10.1016/j.biortech.2012.11.106

[18] International Agency for Research on Cancer (IARC), http://monographs.iarc.fr/ENG/ Classification/latest_classif.php 